\title{
Commentary \\ Cyclin D1 and mammary carcinoma: new insights from transgenic mouse models
}

\author{
Robert L Sutherland and Elizabeth A Musgrove \\ Cancer Research Program, Garvan Institute of Medical Research, St Vincent's Hospital, Sydney, Australia
}

Correspondence: Robert L Sutherland, Cancer Research Program, Garvan Institute of Medical Research, 384 Victoria Street, Darlinghurst, NSW 2010, Australia. Tel: +61 29295 8322; fax: +61 29295 8321; e-mail: r.sutherland@garvan.org.au

Received: 9 November 2001

Accepted: 13 November 2001

Published: 30 November 2001
Breast Cancer Res 2002, 4:14-17

(C) 2002 BioMed Central Ltd

(Print ISSN 1465-5411; Online ISSN 1465-542X)

\begin{abstract}
Cyclin D1 is one of the most commonly overexpressed oncogenes in breast cancer, with 45-50\% of primary ductal carcinomas overexpressing this oncoprotein. Targeted deletion of the gene encoding cyclin D1 demonstrates an essential role in normal mammary gland development while transgenic studies provide evidence that cyclin D1 is a weak oncogene in mammary epithelium. In a recent exciting development, Yu et al. demonstrate that cyclin D1-deficient mice are resistant to mammary carcinomas induced by c-neu and v-Ha-ras, but not those induced by c-myc or Wnt-1. These findings define a pivotal role for cyclin D1 in a subset of mammary cancers in mice and imply a functional role for cyclin D1 overexpression in human breast cancer.
\end{abstract}

Keywords: breast cancer, cyclin D1, oncogenes, transgenics

\section{Introduction}

Breast cancer is a heterogeneous disease arising from multiple genetic changes in oncogenes and tumour suppressor genes with pivotal roles in the homeostatic control of mammary epithelial cell proliferation, differentiation and death. Aberrations in the expression and function of these genes lead to clonal expansion with subsequent acquisition of invasive and metastatic phenotypes.

An increasing number of genes have been implicated in the evolution of breast cancer, and this list is expected to expand with the development of new genomics tools. Studies to date have relied on correlations between gene mutation, gene expression and breast cancer phenotype to identify candidate genes, with demonstration of function dependent on mechanistic studies in diverse experimental systems. One powerful model system is the genetically modified mouse where several genes induce mammary carcinoma when expressed alone or in combination.
In a major recent advance, the laboratory of Piotr Sicinski has combined transgenic and targeted gene deletion approaches to address the requirement for the cell cycle oncoprotein, cyclin D1, in the induction of mammary carcinoma [1]. These novel data demonstrate that cyclin D1 is essential for the development of mammary cancers induced by c-neu and v-Ha-ras, but not those induced by c-myc or Wnt-1. This is the first genetic evidence of an absolute requirement for cyclin D1 in the formation of a subset of mammary cancers, and supports an expanding literature implicating this oncoprotein in the evolution of human breast cancer.

Cyclin D1 is the product of the CCND1 gene and was first implicated in tumourigenesis following localisation to chromosome $11 \mathrm{q} 13$ [2], a region of the genome that is commonly amplified in a range of human carcinomas including breast cancer [3]. Cyclin D1 plays a pivotal role in the regulation of progression from the $G_{1}$ to the $S$ 
phase of the cell cycle through the formation of active enzyme complexes with cyclin-dependent kinases Cdk4 and Cdk6. These kinases phosphorylate substrates including the retinoblastoma gene product, $\mathrm{pRb}$, thus relieving pRb's inhibitory function on $S$ phase entry [4]. This rate-limiting step in cell cycle progression is regulated by a number of mechanisms including cyclin D1 abundance [4]; consequently, dysregulation of cyclin D1 gene expression or function is a probable contributor to loss of normal cell cycle control during carcinogenesis.

\section{Cyclin D1 in breast cancer}

Chromosome $11 \mathrm{q} 13$ is amplified in $\sim 15 \%$ of primary breast cancers, and cyclin D1 is currently the most probable candidate oncogene at this locus [3]. The early demonstration that cyclin D1 mRNA was overexpressed in $\sim 45 \%$ of breast carcinomas identified cyclin D1 as one of the most frequently overexpressed oncogenes in primary breast cancer [5], an observation subsequently confirmed by immunohistochemical studies $[6,7]$.

There has been some debate as to when cyclin D1 overexpression is first observed in the evolution of breast cancer. In situ hybridisation studies suggest that cyclin D1 overexpression occurs at the transition from in situ to invasive cancer [8], while immunohistochemical studies of preneoplastic lesions demonstrate that overexpression was already apparent in hyperplasia and increased with increasing malignancy [9]. If substantiated by further studies, the latter data are compatible with a potential role for cyclin D1 in the early phases of breast cancer development.

Studies on primary breast cancers indicate that overexpression is confined to specific phenotypes, implying different roles in different subtypes of the disease. Lobular carcinoma appears to universally overexpress cyclin D1 [10], while overexpression in ductal carcinoma is confined almost exclusively to oestrogen receptor positive cases [5]. A potential functional link between oestrogen receptor positivity and cyclin D1 overexpression is supported by evidence that cyclin D1 plays a major role in oestrogeninduced mitogenesis in breast cancer cells [11].

\section{Cyclin D1 in mammary gland development and carcinogenesis}

Mammary development is impaired in cyclin D1 null mice such that, although the basic ductal structure forms normally at puberty, alveoli do not develop during pregnancy and lactation does not occur $[12,13]$. This defect does not appear to reflect a necessity for cyclin D1 per se, since epithelium lacking both cyclin D1 and p27 can form a normal mammary gland [14], as can epithelium in which cyclin D1 has been replaced by cyclin E [15]. Instead, it appears that the specific requirement is for timely epithelial cell proliferation.
Overexpression of cyclin D1 in the virgin mammary gland causes increased proliferation and precocious alveolar development, mimicking early pregnancy [16]. These mouse mammary tumour virus (MMTV)-cyclin D1 mice eventually develop mammary adenocarcinomas, with a mean age at onset of $\sim 18$ months [16]. This is a considerably longer timeframe than those observed for MMTV-myc mice ( 11 months), MMTV-Ha-ras mice ( 5.6 months) or MMTV-neu ( 3 months) mice [17,18]. While the oncogenic capacity of these genes in mammary tissue is clear, the long latencies of c-myc-induced and cyclin D1induced tumours in particular indicate that, on their own, they are weak oncogenes and may require cooperating oncogenes for efficient carcinogenesis. Indeed, almost one-half of the tumours induced by tetracycline-regulated c-Myc expression also acquired mutations in $\mathrm{K}$-ras or $\mathrm{N}$ ras [19], complementing early data demonstrating that tumour incidence in the presence of both MMTV-myc and MMTV-Ha-ras was accelerated compared with either oncogene alone [18].

\section{Cooperation between oncogenes in mammary carcinogenesis}

The data outlined above focus attention on a critical question: are there preferred pathways that cooperate with cyclin D1 to promote mammary carcinogenesis? The publication of $\mathrm{Yu}$ et al. [1] addresses this issue and, importantly, indicates preferential cooperation with c-neu and $\mathrm{v}$-Ha-ras. These experiments provide further strong evidence for a critical role for cyclin D1 in the development of mammary cancer, but also raise additional questions about the interaction between different oncogenes in a cell-specific context. What is clearly apparent, and may have been inferred from early studies in cyclin D1 null mice, is that cyclin D1 plays a very specific role in the normal mammary gland and mammary carcinogenesis. The defect in mammary development in cyclin D1 null mice occurs despite the presence of the often redundant D2 and D3 cyclins [1]. Similarly, MMTV-neu-induced and MMTV-ras-induced tumourigenesis was not impaired in cyclin D2 and D3 null mice, and cyclin E could substitute for cyclin D1 in tumourigenesis as well as mammary development [1]. This implies it is the tissue-specific regulation and timing of cyclin D1 expression that is critical to these processes. In support of this concept, increased expression of cyclin D1 but not cyclins D2 and D3 was observed in MMTV-neu-induced and MMTV-ras-induced mammary tumours, while MMTV-Wnt-1-induced and MMTV-mycinduced tumours expressed both cyclins D1 and D2 [1].

The lack of dependence of c-myc-induced tumours of the mammary gland on cyclin D1 is perhaps not surprising given evidence that these two oncogenes act through separate pathways to activate cyclin E-Cdk2 and cell cycle progression in breast cancer cells [20]. Evidence from other model systems that cyclin D2 is a Myc-induced 
gene that contributes to cyclin E-Cdk2 activation through sequestration of $\mathrm{p} 27^{\mathrm{Kip} 1}$ into cyclin D2-cyclin-dependent kinase complexes similarly supports the data presented by Yu et al. It is noteworthy, however, that in the lymphoid system there is strong cooperativity between cyclin D1 and c-myc in lymphomagenesis [21], again illustrating the cell specificity of oncogene interactions in tumourigenesis.

The Wnt-1 oncogene has major effects on mammary gland development and is a potent oncogene in mammary epithelium. Wnt-1 induced precocious mammary gland development in cyclin D1 null mice, indicating that it could replace cyclin D1 function in both development and tumourigenesis [1]. Such data do not support the view that Wnt signalling through accumulation of $\beta$-catenin and, consequently, increased cyclin D1 gene expression is a major pathway in mammary epithelium, as has been proposed in other tissues [22]. While this pathway is probably intact in the mammary gland and breast cancer [23], the present data support a role for Wnt-1 induction of cyclin D2 as a significant downstream effector in mammary epithelium.

\section{Conclusions}

Taken together, these data provide compelling evidence for a requirement for appropriate regulation of cyclin D1 gene expression in the development of the mouse mammary gland and the induction of tumours by c-neu and $\mathrm{v}$-Ha-ras. This appears to relate to the temporal expression of the gene rather than its function since a cyclin E knockin at the cyclin D1 locus can restore normal function. In light of the induction of cyclin D2 by c-myc and Wnt-1, it might be expected that a cyclin D2 knockin would produce a similar phenotype.

Finally, Yu et al. suggest that their data provide strong evidence for targeting cyclin D1 for potential therapeutic intervention in breast cancer, particularly those with activated Neu-Ras pathways [1]. While their data are not incompatible with such a conclusion, there are a number of factors that suggest this is unlikely to be a priority area in the immediate future. Several drugs are currently in advanced preclinical and clinical development targetting the c-erbB-2 receptor, its tyrosine kinase domain [24] and several downstream signalling targets [25]. Furthermore, c-erbB-2 overexpressing tumours, being predominantly oestrogen receptor negative, are unlikely to overexpress cyclin D1. If cyclin D1 overexpression is an early initiating event in the development of breast cancer, however, novel therapeutic strategies that inhibit its aberrant expression or function may well have a role in the ultimate prevention of a significant proportion of breast cancers. Only time and further insightful experiments into the control of cyclin D1 expression and function in mammary epithelium, as reported by Sicinski and colleagues, will determine whether patients will ultimately benefit from these important biological advances.

\section{Acknowledgements}

This work was supported in part by grants from the National Health and Medical Research Council of Australia, The Cancer Council New South Wales, and the US Army Medical Research and Materiel Command (DAMD17-99-9184 and DAMD17-00-1-0252).

\section{References}

1. Yu Q, Geng Y, Sicinski P: Specific protection against breast cancers by cyclin D1 ablation. Nature 2001, 411:1017-1021.

2. Motokura T, Bloom T, Kim HG, Jüppner H, Ruderman J, Kronenberg $\mathrm{H}$, Arnold A: A novel cyclin encoded by a bc/1-linked candidate oncogene. Nature 1991, 350:512-515.

3. Fantl V, Smith R, Brookes S, Dickson C, Peters G: Chromosome 11 q13 abnormalities in human breast cancer. Cancer Surveys 1993, 18:77-93.

4. Sherr CJ: Cancer cell cycles. Science 1996, 274:1672-1677.

5. Buckley MF, Sweeney KJE, Hamilton JA, Sini RL, Manning DL, Nicholson RI, deFazio A, Watts CKW, Musgrove EA, Sutherland $\mathrm{RL}$ : Expression and amplification of cyclin genes in human breast cancer. Oncogene 1993, 8:2127-2133.

6. Bartkova J, Lukas J, Müller H, Lützhøft D, Strauss M, Bartek J: Cyclin D1 protein expression and function in human breast cancer. Int J Cancer 1994, 57:353-361.

7. Gillett C, Fantl V, Smith R, Fisher C, Bartek J, Dickson C, Barnes $D$, Peters G: Amplification and overexpression of cyclin D1 in breast cancer detected by immunohistochemical staining. Cancer Res 1994, 54:1812-1817.

8. Weinstat-Saslow D, Merino MJ, Manrow RE, Lawrence JA, Bluth RF, Wittenbel KD, Simpson JF, Page DI, Steeg PS: Overexpression of cyclin D1 mRNA distinguishes invasive and in situ breast carcinomas from non-malignant lesions. Nat Med 1995, 1:1257-1260.

9. Alle KM, Henshall SM, Field AS, Sutherland RL: Cyclin D1 protein is overexpressed in hyperplasia and intraductal carcinoma of the breast. Clinical Cancer Res 1998, 4:847-854.

10. Oyama T, Kashiwabara K, Yoshimoto K, Arnold A, Koerner F: Frequent overexpression of the cyclin D1 oncogene in invasive lobular carcinoma of the breast. Cancer Res 1998, 58:28762880.

11. Prall OWJ, Sarcevic B, Musgrove EA, Watts CKW, Sutherland $\mathrm{RL}$ : Estrogen-induced activation of Cdk4 and Cdk2 during G1-S phase progression is accompanied by increased cyclin D1 expression and decreased cyclin-dependent kinase inhibitor association with cyclin E-Cdk2. J Biol Chem1997, 272:10882-10894.

12. Fantl V, Stamp G, Andrews A, Rosewell I, Dickson C: Mice lacking cyclin D1 are small and show defects in eye and mammary gland development. Genes Dev 1995, 9:2364-2372.

13. Sicinski P, Liu Donaher J, Parker SB, Li T, Fazeli A, Gardner H, Haslam SZ, Bronson RB, Elledge SJ, Weinberg RA: Cyclin D1 provides a link between development and oncogenesis in the retina and breast. Cell 1995, 82:621-630.

14. Geng Y, Yu Q, Sicinska E, Das M, Bronson RT, Sicinski P: Deletion of the p27Kip1 gene restores normal development in cyclin D1-deficient mice. Proc Natl Acad Sci USA 2001, 98: 194-199.

15. Geng Y, Whoriskey W, Park MY, Bronson RT, Medema RH, Li T, Weinberg RA, Sicinski P: Rescue of cyclin D1 deficiency by knockin cyclin E. Cell 1999, 97:767-777.

16. Wang TC, Cardiff RD, Zukerberg L, Lees E, Arnold A, Schmidt EV: Mammary hyperplasia and carcinoma in MMTV-cyclin D1 transgenic mice. Nature 1994, 369:669-671.

17. Muller WJ, Sinn E, Pattengale PK, Wallace R, Leder P: Singlestep induction of mammary adenocarcinoma in transgenic mice bearing the activated c-neu oncogene. Cell 1988, 54:105-115.

18. Sinn E, Muller WJ, Pattengale P, Tepler I, Wallace R, Leder P: Coexpression of MMTV/v-Ha-ras and MMTV/c-myc genes in transgenic mice: synergistic action of oncogenes in vivo. Cell 1987, 49:465-475.

19. D'Cruz CM, Gunther EJ, Boxer RB, Hartman JL, Sintasath L, Moody SE, Cox JD, Ha SI, Belka GK, Golant A, Cardiff RD, Chodosh LA: c-MYC induces mammary tumorigenesis by means of a preferred pathway involving spontaneous Kras2 mutations. Nat Med 2001, 7:235-239. 
20. Prall OWJ, Rogan EM, Musgrove EA, Watts CKW, Sutherland $\mathrm{RL}$ : c-Myc or cyclin D1 mimics estrogen effects on cyclin E-Cdk2 activation and cell cycle reentry. Mol Cell Biol 1998, 18:4499-4508.

21. Bodrug S, Warner BJ, Bath ML, Lindeman GJ, Harris AW, Adams JM: Cyclin D1 transgene impedes lymphocyte maturation and collaborates in lymphomagenesis with the myc gene. EMBO J 1994, 13:2124-2130

22. Rimmerman RA, Gellert-Randelman A, Diehl JA: Wnt and MEK1 cooperate to promote cyclin D1 accumulation and cellular transformation. J Biol Chem 2000, 275:14736-14742.

23. Lin S-Y, Xia W, Wang JC, Kwong KY, Spohn B, Wen Y, Pestell $R G$, Hung $M-C$ : $\beta$-catenin, a novel prognostic marker for breast cancer: Its roles in cyclin D1 expression and cancer progression. Proc Natl Acad Sci USA 2000, 97:4262-4266.

24. Adjei AA: Blocking oncogenic Ras signaling for cancer therapy. J Nat/ Cancer Inst 2001, 93:1062-1074.

25. Yu D, Hung M-C: Role of erbB2 in breast cancer chemosensitivity. BioEssays 2000, 22:673-680. 